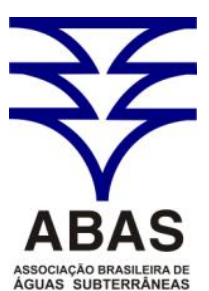

ASSOCIACAO BRASLLERADE
AGUAS SUBTERRANEAS www.abas.org

\section{HIDROGEOQUÍMICA DAS ÁGUAS SUBTERRÂNEAS DO AQUÍFERO SERRA GERAL NA PORÇÃO CENTRO SUL DO ESTADO DE SÃO PAULO}

\author{
GROUNDWATER HYDROGEOCHEMISTRY FROM SERRA GERAL \\ AQUIFER IN THE SOUTHERN PORTION OF THE SÃO PAULO STATE \\ (BRAZIL)
}

Didier Gastmans ${ }^{1}$, Amauri Antonio Menegário², Cinthia Cristine Moura ${ }^{3}$

\begin{abstract}
Groundwater from Serra Geral Aquifer (SGA) represents an important source for water supply in the Southern portion of São Paulo state (Brazil). Due the importance of the aquifer, the evaluation of hydrogeochemical process might subsidies the understanding of groundwater flow conditions. Groundwater of SGA in the Southern portion of São Paulo state presents low salinity, and $\mathrm{pH}$ 's varying from neutral to alkaline conditions. Two main hydrochemical facies are recognized: $\mathrm{Ca}-\mathrm{Mg}-\mathrm{HCO}_{3}$ e $\mathrm{Na}-\mathrm{HCO}_{3}$ type. High levels of nitrate and chloride are observed in some groundwater samples, which are associated to anthropic activities. The natural geochemical process observed, responsible by the chemical composition of groundwater, are ass ociated to mineral dissolution under $\mathrm{CO}_{2}$ open conditions. Carbonate precipitation, with calcium and magnesium removal, associated ion exchange process, could be explain the occurrence of $\mathrm{Na}-\mathrm{HCO}_{3}$ groundwater type, however ascending groundwater flow from underlying aquifer (Guarani Aquifer System) seem to be responsible by the composition of the more saline groundwater.
\end{abstract}

Keywords: Serra Geral Aquifer System. Basalts. Water-rock interaction. Hydrochemistry.

Resumo: As águas subterrâneas do Aquífero Serra Geral (ASG), na porção centro sul do estado de São Paulo, representam uma importante fonte para o abastecimento público de água potável, nesse sentido a avaliação dos processos resultantes da interação água-rocha, associados a evolução hidrogeoquímica dessas águas, podem fornecer subsídios para a compreensão das condições de fluxo na unidade. As águas do ASG na área de estudo apresentam baixas salinidades, com $\mathrm{pH}$ 's variando de neutros a alcalinos, sendo distinguidas duas fácies hidroquímicas principais: fácies $\mathrm{Ca}-\mathrm{Mg}-\mathrm{HCO}_{3}$ e $\mathrm{Na}-\mathrm{HCO}_{3}$. Altas concentrações de nitrato e cloreto são observadas em algumas amostras, e estão associadas à contaminação do aquífero pela ação antrópica. Os processos geoquímicos naturais que conduzem a composição dessas águas estão associados à dissolução dos minerais constituintes dos basaltos mediante a inserção de $\mathrm{CO}_{2}$ no sistema. A precipitação de carbonatos, com remoção de cálcio e magnésio, associada a processos de troca iônica, podem explicar a ocorrência de águas $\mathrm{Na}-\mathrm{HCO}_{3}$, entretanto nas águas com maior salinização, fluxos ascendentes do aquífero sotoposto (Sistema Aquífero Gu arani), seriam responsáveis pela composição dessas águas.

Palavras-chave: Sistema Aquífero Serra Geral. Basaltos. Interação água-rocha. Hidroquímica.

\title{
INTRODUÇÃO
}

A associação entre a excelente qualidade de suas águas subterrâneas, e a grande extensão dos derrames basálticos, faz com que os recursos hídricos provenientes dos aquíferos associados a estas litologias sejam aproveitados para o abastecimento em várias partes do globo. Dentre as principais unidades aquíferas basálticas, podemos destacar: os aquíferos relacionados aos basaltos da província de Deccan na Índia (DEOLANKAR, 1980), do Columbia River Plateau na América do Norte (DEUTSCH et al., 1982), das Montanhas de Golan em Israel (DAFNY et al., 2006), dos Atheron Tablelands em North Queensland na Austrália (LOCSEY \& COX, 2003), além dos derrames

\footnotetext{
${ }^{1}$ Centro de Estudos Ambientais - UNESP Rio Claro (gastmans@rc.unesp.br).

${ }^{2}$ Centro de Estudos Ambientais - UNESP Rio Claro (amenega@rc.unesp.br).

${ }^{3}$ Centro de Estudos Ambientais - UNESP Rio Claro (cinthia.mr@gmail.com).
} 
associados à Formação Serra Geral, na porção sudeste do continente sul americano, ocupando parte dos territórios de Argentina, Brasil, Paraguai e Uruguai, e que constitui uma das mais importantes manifestações magmáticas do globo.

Os basaltos da Formação Serra Geral representam uma das mais importantes unidades aquíferas da Bacia do Paraná. O Aquífero Serra Geral (ASG), e seus recursos são utilizados para o abastecimento público, especialmente nos estados da região Sul do Brasil (Paraná, Santa Catarina e Rio Grande do Sul) e em Mato Grosso do Sul. Em função de sua importância para essas regiões, a unidade foi objeto de inúmeros estudos hidroquímicos, que possibilitaram a caracterização de suas águas e a definição de suas relações hidráulicas com a unidade sotoposta, o Sistema Aquífero Guarani (SAG) (p.ex. BITTENCOURT, 1996; BITTENCOURT et al., 2003, BOFF et al., 2006; BUCHMANN et al., 2002; LASTORIA, 2002; LASTORIA et al., 2005, MACHADO et al., 2002; NANNI, 2008, dentre outros).

Na porção oeste do estado de São Paulo, as águas subterrâneas dos aquíferos mesozoicos da Bacia do Paraná, os sistemas aquíferos Bauru, Serra Geral e Guarani, representam uma importante fonte de suprimento de água. Nesse contexto, a ampliação do conhecimento a respeito dessas unidades servirá de subsídio aos gestores dos recursos hídricos, possibilitando a adoção de medidas para a utilização racional das águas subterrâneas contidas nessas unidades.

Enquanto existe literatura abundante referente aos sistemas aquíferos Bauru (SAB) e Guarani (SAG) no estado de São Paulo (p.ex. GALLO \& SINELLI, 1980; SILVA, 1983; KIMMELMANN e SILVA et al., 1986; REBOUÇAS, 1994; CAMPOS, 1987 e 1993; MENG \& MAYNARD, 2001; SRACEK \& HIRATA, 2002; BARISON, 2003; PAULA e SILVA et al., 2005 ; GASTMANS et al., 2010; dentre outros), muito pouco conhecimento se produziu em relação ao conhecimento hidrogeológico e hidroquímico do ASG, especialmente quando se busca conhecer a relação existente entre o arcabouço geológico dos derrames da Formação Serra Geral, a ação antró- pica e o quimismo das águas subterrâneas. Nesse sentido, o objetivo do presente trabalho é apresentar uma avaliação hidroquímica das águas subterrâneas do ASG na porção centro-sul do estado de São Paulo, que possa conduzir a um modelo hidrogeoquímico conceitual para a unidade, considerando para tanto a ação antrópica, a evolução natural, produto da interação entre a água subterrânea e os basaltos bem como as relações com as unidades aquíferas sotoposta e sobreposta.

\section{CARACTERIZAÇÃO DA ÁREA DE ESTU- DO}

A área de estudo está localizada na porção centro sul do estado de São Paulo, na margem direita do curso médio do Rio Paranapanema, que constitui a Unidade de Gerenciamento de Recursos Hídricos - UGRHI 17 (Figura 1), onde se localizam importantes centros urbanos, como Marília, Ourinhos, Assis, dentre outros.

Nas proximidades do Rio Paranapanema afloram basaltos associados à Formação Serra Geral, recobertos a norte pelos sedimentos continentais de idade cretácea do Grupo Bauru. A região encontra-se inserida no compartimento geomorfológico do Planalto Ocidental, que constitui a continuidade física do reverso das Cuestas Basálticas, situadas a leste da área de estudo. O relevo da região é constituído essencialmente por colinas, amparados essencialmente pelos sedimentos do Grupo Bauru e os derrames basálticos da Formação Serra Geral. Nas proximidades da cidade de Marília ocorrem morrotes alongados e espigões, sustentado pelos arenitos cimentados da Formação Marília. As cotas topográficas variam entre 650 metros no Planalto de Marília até cerca de 350 metros nas proximidades do Rio Paranapanema (CBH-MP, 1999).

A precipitação pode alcançar 1500 $\mathrm{mm} / \mathrm{ano}$, com distribuição caracterizada por verões chuvosos e invernos secos. As temperaturas médias dos meses mais quentes são superiores a $22^{\circ} \mathrm{C}$, enquanto as mínimas observadas durante o inverno podem alcançar temperaturas negativas (CBH-MP, 1999). 


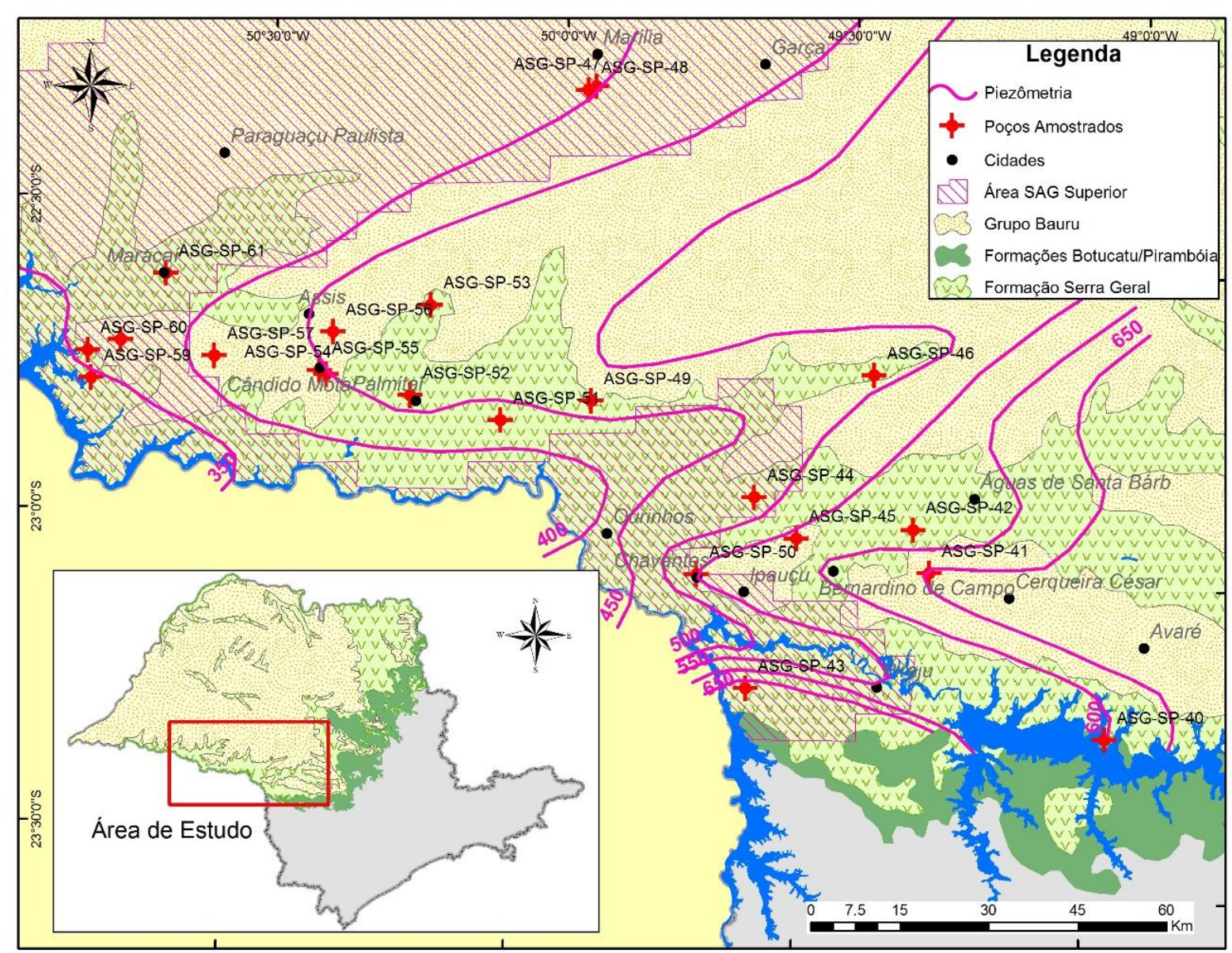

Figura 1 - Mapa hidrogeológico simplificado da área, com a localização dos poços amostrados, piezometria simplificada do ASG e zonas com possível fluxo ascendente do SAG

Figure 1 - Hydrogeological map showing the location of sampled wells, simplified potentiometric surface of SGA and also showing the possible zone with ascending flow from GAS toward ASG

\section{ASPECTOS GEOLÓGICOS E HIDROGEO- LÓGICOS DA FORMAÇÃO SERRA GERAL}

A Província Magmática do Paraná (PMP) constitui uma das maiores manifestações ígneas vulcânicas de caráter básico em áreas continentais no globo, representando, segundo Milani et al. (1994), importante contribuição para a geração de crosta continental durante o Mesozoico. A essa atividade magmática estão associados derrames basálticos e rochas intrusivas (sills e diques) de caráter básico da Formação Serra Geral, com idades que variam entre 133 e $132 \mathrm{Ma}$ (ERNESTO et al., 1999), e que se estendem sobre a área de ocorrência da Bacia Sedimentar do Paraná e adjacências.

Diferenças petrográficas e geoquímicas permitem o reconhecimento de três litotipos principais na Formação Serra Geral: basaltos e andesitos associados ao conjunto de rochas básicasintermediárias, que representam $97 \%$ de todo o volume magmático; riodacitos e riolitos do tipo Palmas (ATP) e os riodacitos e quartzo latitos do tipo Chapecó (ATC), que representam respecti- vamente 2,5 e $0,5 \%$ do volume magmático, e com área de ocorrência principalmente na região sul do Brasil (BELLIENI et al., 1986; NARDY et al., 2002).

No estado de São Paulo ocorrem essencialmente os basaltos da unidade básicaintermediária, constituídos por plagioclásio (essencialmente labradorita), piroxênio (augita e piegonita) e olivina (principalmente sob a forma de pseudomorfos), com porcentagem modal respectivamente de $25-50 \%, 20-40 \%$ e $4 \%$. Como acessórios são reconhecidos: magnetita e ilmenita em quantidade que variam de 4 a $10 \%$, além de mesóstase (vítrea ou microgranular), que pode chegar a representar $40 \%$ do volume total nas rochas com textura intergranular (MACHADO et al., 2007). Nos limites entre derrames são reconhecidas zonas vesiculares, com espessuras variáveis, preenchidas por material secundário, formando amígdalas de quartzo, calcita, zeólitas, fluorita e comumente argilas de coloração esver- 
deada, provavelmente do grupo da celadonita (MACHADO, 2007).

Uma sucessão de derrames de rochas vulcânicas ácidas, com espessuras que podem alcançar 150 metros, foi reconhecida na região de Piraju e Ourinhos por Janasi et al. (2007). Esses derrames são constituídos em sua porção central por dacitos porfiríticos de coloração cinza com baixa proporção de vidro e vesículas, e que gradam para variedades vítreas fortemente vesiculadas em direção aos contatos superiores e inferiores desses derrames.

A estruturação interna dos derrames basálticos possibilita a geração de um sistema de descontinuidades particulares, definidos por diversos autores como os principais responsáveis pelo condicionamento do fluxo das águas subterrâneas no interior de aquíferos basálticos (DEOLONKAR, 1980, LÉONARDI et al., 1996, DAFNY et al. 2006, LASTORIA et al., 2006; dentre outros). Esse modelo é sintetizado por Rebouças \& Fraga (1988), que subdividem cada derrame de lavas em duas unidades: uma superior de alta permeabilidade, representada pelo produto da alteração intempérica dos basaltos, limitado na base por uma descontinuidade física, e uma unidade inferior, associada a base dos derrames e também limitada por uma descontinuidade. Essas duas unidades, de topo e base de derrames representariam a zona preferencial de circulação da água subterrânea, associada as estruturas vesiculares e ao intenso fraturamento horizontal. A conexão vertical de fluxo entre esses distintas zonas de circulação, estaria associada as diáclases existentes na porção central do derrame.

Esse modelo de fluxo também foi reconhecido nos basaltos da região de Ribeirão Preto por Wahnfried (2010) e Fernandes et al. (2010), que avaliaram a sua relação com a recarga da unidade aquífera imediatamente sotoposta, o Sistema Aquífero Guarani, identificando a predominância de fluxos horizontais nas descontinuidades dos basaltos, e a inexistência de fluxo vertical descendente através dos lineamentos geológicos, identificados por meio de levantamentos aerofotogramétricos, que possibilitassem a recarga do SAG por água proveniente dos basaltos.

Quimicamente as águas subterrâneas do ASG no Estado de São Paulo geralmente apresentam baixas condutividades elétricas e, consequentemente, baixos conteúdos em sólidos totais dissolvidos, com amplo espectro de variação do $\mathrm{pH}$, conferindo características desde ácidas a alcalinas às águas do aquífero. Em função de sua composição química as águas são geralmente classificadas como bicarbonatadas cálcicas e cálcio- magnesianas (DAEE, 1974 e 1976; CAMPOS, 1993).

Na região noroeste do estado foram reconhecidas algumas anomalias hidroquímicas, caracterizadas por valores de resíduo seco superiores a $200 \mathrm{mg} / \mathrm{L}$, e que foram associadas a regiões de ocorrência de fraturas ou falhas preenchidas por mineralização hidrotermal, ou ainda contaminação por águas oriundas de aquíferos mais profundos por fluxo ascendente (DAEE, 1976).

Ocorrências de concentrações de flúor nas águas do ASG, acima dos limites permitidos, foram observadas por Perroni et al. (1985) em águas com elevadas concentrações de sódio e em poços situados em uma faixa ao longo dos principais alinhamentos estruturais reconhecidos na Bacia do Paraná, o que levou os autores a aventarem um possível condicionamento estrutural para esse fenômeno.

Na região sudoeste do estado do Paraná águas subterrâneas captadas em poços perfurados no ASG apresentam composição predominantemente $\mathrm{Ca}-\mathrm{HCO}_{3}$ e secundariamente $\mathrm{Na}-\mathrm{HCO}_{3}$, associada essencialmente à processos de interação água-rocha (MANASSES et al., 2007), entretanto ao longo das principais estruturas geológicas que cortam o estado, Bittencourt et al. (2003) e Rosa Filho et al. (2006) observam inúmeras ocorrências de águas $\mathrm{Na}_{-} \mathrm{SO}_{4}-\mathrm{Cl}$ em poços perfurados nos basaltos, que inclusive chegam a tornar a água imprópria ao consumo. Esses autores associam essas ocorrências a fluxos ascendentes de águas provenientes do SAG.

\section{MATERIAIS E MÉTODOS}

Foram coletadas 22 amostras de água subterrâneas entre os dias 05 e 08 de março de 2013, provenientes de poços tubulares perfurados no ASG e utilizados para o abastecimento público. A localização desses poços pode ser visualizada na figura 1.

Em campo foram medidos o $\mathrm{pH}$ e a condutividade elétrica. As amostras foram filtradas em filtro de acetato de celulose $0,45 \mu \mathrm{m}$, e duas alíquotas separadas em frascos de polietileno de $300 \mathrm{~mL}$; a primeira preservada apenas sob refrigeração, destinada a análise de ânions, e a segunda preservada com a adição de ácido nítrico até $\mathrm{pH}$ inferior a 2, destinada a determinação de cátions.

As análises foram realizadas no Laboratório de Hidrogeologia e Hidroquímica do Departamento de Geologia Aplicada do IGCE/UNESP Rio Claro. A alcalinidade foi determinada por titulação, os ânions: $\mathrm{F}^{-}, \mathrm{Cl}^{-}, \mathrm{NO}_{3}^{-}, \mathrm{PO}_{4}{ }^{2-}$ e $\mathrm{SO}_{4}{ }^{2-}$ determinados por cromatografia de íons, enquanto 
as concentrações dos cátions: $\mathrm{Na}^{+}, \mathrm{K}^{+}, \mathrm{Ca}^{2+}, \mathrm{Mg}^{2+}$ e $\mathrm{SiO}_{2}$, por meio de espectrometria de emissão atômica com fonte de plasma e argônio induzido (ICP-AES). Os resultados dos parâmetros físicos químicos e das análises químicas efetuadas são apresentados na tabela 1 .

A avaliação da qualidade dos resultados analíticos foi feita por meio do cálculo do balanço iônico. Para este estudo foi convencionado um erro inferior a $7 \%$ como aceitável, entretanto foram consideradas as análises das amostras ASGSP-47 e ASG-SP-48, que apresentaram erros superiores, mas aceitáveis para serem avaliados no presente trabalho.

A análise estatística multivariada dos dados hidroquímicos foi realizada com o auxílio do software Statistica, e os cálculos de especiação e determinação dos índices de saturação com a uti- lização do software PHREEQC (PARKHURST \& APPELO, 1999).

A potenciometria simplificada do ASG para a área (Figura 1), indicativa das direções principais de fluxo das águas subterrâneas, foi construída a partir de dados dos poços amostrados, existentes nas seguintes bases de dados: SIDAS-DAEE e SIAGAS-CPRM. Quando a informação referente ao poço amostrado não estava disponível, foram utilizados dados de outros poços perfurados naquela localidade. Esses dados, bem como as fontes, são apresentados na tabela 1.

Para a comparação entre as superfícies piezométricas do ASG e do SAG na área de estudos, foi tomada a superfície piezométrica do SAG elaborada por Gastmans \& Chang (2012), baseada em um conjunto de dados de poços perfurados no SAG no estado de São Paulo. 
Tabela 1 - Dados hidroquímicos e piezométricos

Table 1 - Hydrochemical and piezometric data set

\begin{tabular}{|c|c|c|c|c|c|c|c|c|c|c|c|c|c|c|c|c|c|c|c|}
\hline \multirow{3}{*}{ Código Amostra } & \multirow{3}{*}{ Cidade } & \multirow{3}{*}{$\begin{array}{c}\text { Cota } \\
\text { NA } \\
(\mathrm{m})\end{array}$} & \multirow{3}{*}{$\frac{\mathrm{CE}}{(\mu \mathrm{S} / \mathrm{cm})}$} & \multirow{3}{*}{ pH } & \multirow{2}{*}{ Temp } & \multicolumn{2}{|c|}{ Alcalinidade } & \multirow{2}{*}{$\mathrm{Na}$} & \multirow{2}{*}{$\mathbf{K}$} & \multirow{2}{*}{$\mathrm{Ca}$} & \multirow{2}{*}{ Mg } & \multirow{2}{*}{$\mathbf{F}$} & \multirow{2}{*}{ Cl } & \multirow{2}{*}{$\mathrm{NO}_{3}$} & \multirow{2}{*}{$\mathrm{PO}_{4}$} & \multirow{2}{*}{$\mathrm{SO}_{4}$} & \multirow{3}{*}{$\mathbf{S i}$} & \multirow{3}{*}{$\frac{\text { Erro }}{\%}$} & \multirow{3}{*}{ Class. HQ } \\
\hline & & & & & & $\mathrm{HCO}_{3}$ & $\mathrm{CO}_{3}$ & & & & & & & & & & & & \\
\hline & & & & & $\left({ }^{\circ} \mathrm{C}\right)$ & \multicolumn{11}{|c|}{$(\mathrm{mg} / \mathrm{L})$} & & & \\
\hline ASG-SP-40 & Avaré & $595^{1}$ & 48,3 & 6,4 & 23,3 & 33,1 & 0,0 & 1,66 & 3,36 & 6,56 & 1,42 & 0,05 & 0,27 & 0,25 & 0,31 & 0,14 & 11,50 & 3,67 & $\mathrm{Ca}-\mathrm{Mg}-\mathrm{HCO}_{3}$ \\
\hline ASG-SP-41 & Manduri & $656^{2}$ & 31,6 & 7,1 & 23,8 & 13,7 & 0,0 & 2,42 & 0,68 & 3,07 & 0,69 & 0,05 & 0,54 & 3,51 & $<0,08$ & 0,039 & 6,90 & 5,19 & $\mathrm{Ca}-\mathrm{Mg}-\mathrm{HCO}_{3}$ \\
\hline ASG-SP-42 & Óleo & $580^{2}$ & 200,0 & 8,0 & 23,3 & 105,0 & 0,0 & 7,98 & 0,97 & 27,90 & 6,12 & 0,061 & 4,66 & 10,70 & $<0,08$ & $<0,02$ & 23,70 & 5,57 & $\mathrm{Ca}-\mathrm{Mg}-\mathrm{HCO}_{3}$ \\
\hline ASG-SP-43 & Timburi & $685^{3}$ & 108,2 & 6,8 & 22,6 & 49,7 & 0,0 & 3,75 & 2,81 & 9,93 & 4,70 & 0,057 & 3,88 & 6,46 & 0,60 & 0,57 & 15,20 & 3,44 & $\mathrm{Ca}-\mathrm{Mg}-\mathrm{HCO}_{3}$ \\
\hline ASG-SP-44 & S.C.do Rio Pardo & $467^{2}$ & 204,0 & 7,8 & 23,9 & 104,0 & 0,0 & 36,20 & 0,36 & 8,20 & 2,30 & 0,075 & 4,99 & 14,10 & $<0,08$ & 1,09 & 16,90 & 1,94 & $\mathrm{Na}-\mathrm{HCO}_{3}$ \\
\hline ASG-SP-45 & S.C.do Rio Pardo & $590^{2}$ & 116,0 & 6,4 & 23,4 & 39,1 & 0,0 & 3,40 & 1,28 & 11,80 & 4,90 & 0,057 & 5,28 & 16,20 & 0,36 & $<0,02$ & 20,70 & 5,31 & $\mathrm{Ca}-\mathrm{Mg}-\mathrm{HCO}_{3}$ \\
\hline ASG-SP-46 & Esp.Sto. Turvo & $486^{2}$ & 163,0 & 7,3 & 26,0 & 78,9 & 0,0 & 3,84 & 1,91 & 18,90 & 7,42 & 0,058 & 4,64 & 10,40 & 0,60 & 0,18 & 24,20 & 5,08 & $\mathrm{Ca}-\mathrm{Mg}-\mathrm{HCO}_{3}$ \\
\hline ASG-SP-47 & Marília & $408^{2}$ & 413,0 & 10,2 & 26,5 & 50,0 & 92,0 & 112,00 & 0,22 & 0,49 & 0,02 & 0,42 & 0,93 & $<0,04$ & $<0,08$ & 5,01 & 17,80 & 9,67 & $\mathrm{Na}-\mathrm{HCO}_{3}$ \\
\hline ASG-SP-48 & Marília & $400^{2}$ & 472,0 & 10,1 & 26,6 & 70,1 & 103,0 & 140,00 & 0,24 & 0,46 & 0,01 & 0,34 & 0,82 & $<0,04$ & $<0,08$ & 3,96 & 21,00 & 13,06 & $\mathrm{Na}-\mathrm{HCO}_{3}$ \\
\hline ASG-SP-49 & Ribeirão do Sul & $470^{1}$ & 158,4 & 8,8 & 26,8 & 91,0 & 4,41 & 36,60 & 0,13 & 2,82 & 0,13 & 0,086 & 0,48 & 0,28 & $<0,08$ & 0,17 & 15,70 & 2,41 & $\mathrm{Na}-\mathrm{HCO}_{3}$ \\
\hline ASG-SP-50 & Chavantes & $562^{3}$ & 240,0 & 9,1 & 28,1 & 129,0 & 14,2 & 49,80 & 0,78 & 9,38 & 1,09 & 0,20 & 0,66 & 0,38 & $<0,08$ & 0,29 & 18,10 & 2,14 & $\mathrm{Na}-\mathrm{HCO}_{3}$ \\
\hline ASG-SP-51 & Ibirarema & $441^{1}$ & 104,0 & 7,8 & 24,4 & 61,0 & 0,0 & 3,30 & 0,96 & 12,80 & 4,58 & 0,041 & 0,69 & 2,36 & 0,40 & $<0,02$ & 19,40 & 5,52 & $\mathrm{Ca}-\mathrm{Mg}-\mathrm{HCO}_{3}$ \\
\hline ASG-SP-52 & Palmital & $489^{2}$ & 64,4 & 7,3 & 24,6 & 38,7 & 0,0 & 2,44 & 0,67 & 7,54 & 2,99 & 0,062 & 0,27 & 0,97 & 0,53 & 0,067 & 19,20 & 5,93 & $\mathrm{Ca}-\mathrm{Mg}-\mathrm{HCO}_{3}$ \\
\hline ASG-SP-53 & Platina & $459^{2}$ & 189,7 & 8,7 & 25,0 & 109,0 & 4,28 & 44,50 & $<0,03$ & 2,45 & 0,55 & 0,12 & 1,24 & 1,91 & $<0,08$ & 0,20 & 15,00 & 2,40 & $\mathrm{Na}-\mathrm{HCO}_{3}$ \\
\hline ASG-SP-54 & Candido Mota & $450^{1}$ & 142,1 & 7,3 & 25,7 & 76,9 & 0,0 & 8,05 & 0,17 & 21,20 & 2,31 & 0,028 & 1,85 & 8,10 & $<0,08$ & $<0,02$ & 13,20 & 5,17 & $\mathrm{Ca}-\mathrm{Mg}-\mathrm{HCO}_{3}$ \\
\hline ASG-SP-55 & Candido Mota & $440^{1}$ & 153,3 & 7,5 & 25,2 & 72,9 & 0,0 & 22,30 & 0,25 & 9,47 & 2,19 & 0,17 & 2,91 & 14,90 & $<0,08$ & 0,62 & 16,10 & 2,85 & $\mathrm{Na}-\mathrm{Ca}-\mathrm{HCO}_{3}$ \\
\hline ASG-SP-56 & Assis & $470^{1}$ & 106,5 & 7,7 & 23,4 & 61,1 & 0,0 & 3,39 & 0,63 & 13,20 & 4,40 & 0,045 & 1,27 & 2,18 & 0,31 & 0,069 & 22,30 & 4,79 & $\mathrm{Ca}-\mathrm{Mg}-\mathrm{HCO}_{3}$ \\
\hline ASG-SP-57 & Tarumã & $421^{2}$ & 124,4 & 7,8 & 23,5 & 75,0 & 0,0 & 7,83 & 0,61 & 13,60 & 4,61 & 0,047 & 1,16 & 1,11 & 0,40 & 0,099 & 21,90 & 4,81 & $\mathrm{Ca}-\mathrm{Mg}-\mathrm{HCO}_{3}$ \\
\hline ASG-SP-58 & Florínea & $365^{1}$ & 152,1 & 7,3 & 23,1 & 67,4 & 0,0 & 10,90 & 0,40 & 14,30 & 4,75 & 0,053 & 4,91 & 14,50 & $<0,08$ & 0,17 & 21,40 & 3,44 & $\mathrm{Ca}-\mathrm{Mg}-\mathrm{HCO}_{3}$ \\
\hline ASG-SP-59 & Ped. Paulista & $338^{2}$ & 121,0 & 7,9 & 24,0 & 69,5 & 0,0 & 6,31 & 0,23 & 16,40 & 3,60 & 0,065 & 1,51 & 3,47 & $<0,08$ & 0,20 & 20,40 & 5,67 & $\mathrm{Ca}-\mathrm{Mg}-\mathrm{HCO}_{3}$ \\
\hline ASG-SP-60 & Cruzália & $350^{2}$ & 123,0 & 8,4 & 25,4 & 65,4 & 1,64 & 15,60 & 0,15 & 13,20 & 0,19 & 0,076 & 2,34 & 2,03 & $<0,08$ & 0,26 & 19,10 & 4,71 & $\mathrm{Ca}-\mathrm{Mg}-\mathrm{HCO}_{3}$ \\
\hline ASG-SP-61 & Maracaí & $375^{2}$ & 153,3 & 8,0 & 25,2 & 106,0 & 0,0 & 13,80 & 0,57 & 24,70 & 6,13 & 0,069 & 6,18 & 11,10 & $<0,08$ & 2,03 & 22,50 & 4,80 & $\mathrm{Ca}-\mathrm{Mg}-\mathrm{HCO}_{3}$ \\
\hline
\end{tabular}

Obs: $\left({ }^{1}\right)$ - nível d'água estimado a partir de dados de poços perfurados na localidade; $\left({ }^{2}\right)$ - nível d'água retirado de dados do SIDAS - DAEE; $\left({ }^{3}\right)$ - nível d'água retirado de dados do SIAGAS - CPRM. 


\section{RESULTADOS E DISCUSSÕES}

A avaliação hidroquímica das águas subterrâneas de aquíferos fraturados e heterogêneos, como é o caso do ASG, vem sendo utilizada cada vez mais como ferramenta auxiliar para o entendimento das condições tão particulares de fluxo nessas unidades. Esses estudos possibilitam a definição das reações naturais, decorrentes da interação água-rocha, que imprimem as características químicas das águas subterrâneas, apontando para linhas de fluxo preferenciais. São utilizados ainda na identificação das alterações promovidas pela ação antrópica sobre essas águas e que modificam as suas características naturais. Entretanto uma avaliação prévia das principais direções de fluxo é necessária, como forma de corroborar essas observações.

A conformação do relevo na área de estudo possui uma grande influência nas principais direções de fluxo das águas subterrâneas do ASG. Nas porções mais altas, situadas à leste da área, ao longo dos divisores de água superficial e controlados pela presença dos sedimentos do Grupo Bauru, estão localizadas às maiores cargas potenciométricas, que, a grosso modo, diminuem em direção a oeste. Esses divisores condicionam a existência de descarga do aquífero ao longo da rede de drenagem que corta as áreas de afloramentos dos basaltos, como ao longo dos rios Pardo e Paranapanema (Figura 1). A existência de um divisor de águas subterrâneas ao norte do Rio Pardo, entre as cidades de Águas de Santa Bárbara e Garça, com direção aproximada EW, deve ser considerado com cuidado, pois não existem dados de poços nessa área, que corroborem definitivamente a existência do mesmo.

O cruzamento dessa superfície piezométrica, com a do Sistema Aquífero Guarani, indica a possibilidade de existência de fluxos ascendentes de águas subterrâneas provenientes do SAG em direção ao ASG, ao longo do Rio Paranapanema e na porção norte da área de estudo, nas proximidades das cidades de Marília (Figura 1), podendo essas águas alcançarem o ASG.

As águas do ASG na porção centro sul do estado de São Paulo possuem uma composição química bastante homogênea e com baixa salinização, conforme já reconhecido por outros autores (DAEE, 1974 e 1976; CAMPOS, 1993), caracterizadas especialmente pelos baixos valores da condutividade elétrica, em sua maioria inferiores a $200 \mu \mathrm{S} / \mathrm{cm}$. Os valores de $\mathrm{pH}$ apontam para águas geralmente neutras a ligeiramente alcalinas, com média de 7,90 e extremos variando de 6,40 a 10,2 (Tabela 1).

O ânion predominante nas águas do ASG é o bicarbonato, que nas amostras com $\mathrm{pH}$ acima de 8,3 ocorre juntamente com o carbonato, enquanto as concentrações de sulfato e cloreto são geralmente baixas. As concentrações de nitrato em algumas amostras alcançam valores superiores a $10 \mathrm{mg} / / \mathrm{L} \mathrm{NO}_{3}$, caracterizando alteração da qualidade da água pela ação antrópica, entretanto em nenhuma das amostras as concentrações de nitrato excedem o limite preconizado pela portaria MS2914/2011 (BRASIL, 2011), que é de $10 \mathrm{mg} / \mathrm{L} \mathrm{N}$ $\mathrm{NO}_{3}$ (equivalente a $45 \mathrm{mg} / \mathrm{L} \mathrm{NO}_{3}$ ).

Em relação às concentrações dos cátions, as amostras podem ser divididas em dois grandes grupos: o primeiro é caracterizado pela relação: $\mathrm{Ca}>\mathrm{Mg} \geq \mathrm{Na}>>\mathrm{K}$, enquanto no segundo a relação observada é: $\mathrm{Na}>\mathrm{Ca}>>\mathrm{Mg}>>\mathrm{K}$. As reações e processos que apontam para essa distinção serão discutidos adiante.

O diagrama de Piper, apresentado na figura 2, mostra que as águas subterrâneas do ASG são classificadas essencialmente como $\mathrm{Ca}-\mathrm{Mg}$ $\mathrm{HCO}_{3}$, com passagem para águas $\mathrm{Na}-\mathrm{HCO}_{3}$, evidenciando as relações apresentadas acima. Um pequeno aumento nas concentrações de cloreto também é observado associado à contaminação antrópica. 


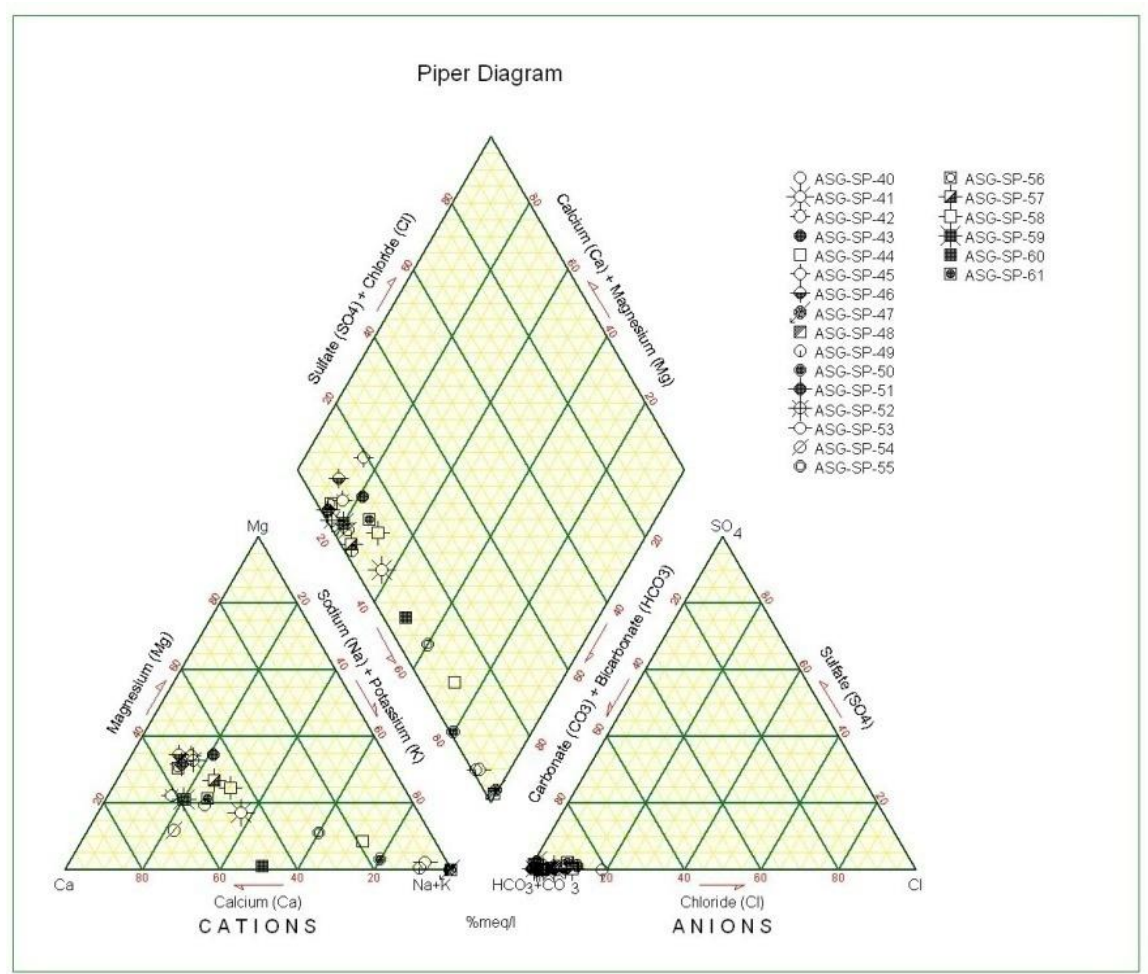

Figura 2 - Diagrama de Piper

Figure 2 - Piper Diagrame

A distribuição das fácies hidroquímicas (Figura 3) mostra que as águas $\mathrm{Ca}-\mathrm{Mg}-\mathrm{HCO}_{3}$ estão concentradas nas porções leste e oeste da área, enquanto as águas $\mathrm{Na}-\mathrm{HCO}_{3} \mathrm{em}$ uma faixa central. Essa distribuição não possui relação aparente com a zona de ocorrência dos derrames de basaltos ácidos descritos por Janasi et al. (2007), indicando que variações na composição química das rochas, apresentam um efeito muito pequeno sobre a distribuição das fácies hidroquímicas.

Observa-se claramente que as águas $\mathrm{Na}-$ $\mathrm{HCO}_{3}$ possuem dois graus de salinização, as águas com maior conteúdo de sais, são àquelas coletadas na cidade de Marília, concordante com a direção de fluxo das águas subterrâneas. Entretanto deve-se considerar as diferenças observadas entre essas amostras e as amostras coletadas ao sul, que também apresentam a mesma tipologia.

\section{Análise Estatística Multivariada}

Técnicas de análise estatística multivariada vêm sendo utilizadas na interpretação de processos hidrogeoquímicos, seja indicando os processos naturais que interferem na composição química das águas subterrâneas (USUNOFF \& GUZMAN-GUZMAN, 1989; MENG \& MAY-
NARD, 2002; GÜLLER et al., 2002; VIDAL et al., 2002; OYEBOG et al., 2012, dentre outros), seja auxiliando na identificação da proveniência das águas subterrâneas em relação a distintos aquíferos (LOCSEY \& COX, 2003; IRAWAN et al., 2009), ou na avaliação da contaminação de aquíferos (SUK \& LEE, 1999).

A aplicação dessas técnicas em estudos hidrogeoquímicos tem como base a investigação das relações estatísticas existentes, entre os constituintes dissolvidos presentes na água subterrânea e fatores ambientais, como a composição do substrato rochoso, ou a ação antrópica, sobre o recurso hídrico. Essas relações estatísticas não necessariamente estabelecem relações de causa e efeito, mas apresentam informações de forma compacta, que permitem a elaboração de hipóteses plausíveis para a interpretação dos dados (DREVER, 1997).

Duas técnicas de estatística multivariada com grande utilidade na avaliação de dados hidrogeoquímicos foram empregadas nesse estudo: a Análise de Agrupamentos (Cluster Analisys) e a Análise de Fatores. O objetivo foi o de delinear os grupos hidroquímicos aos quais pertencem as amostras de água, e os fatores que imprimem as distintas características aos grupos de amostras. 


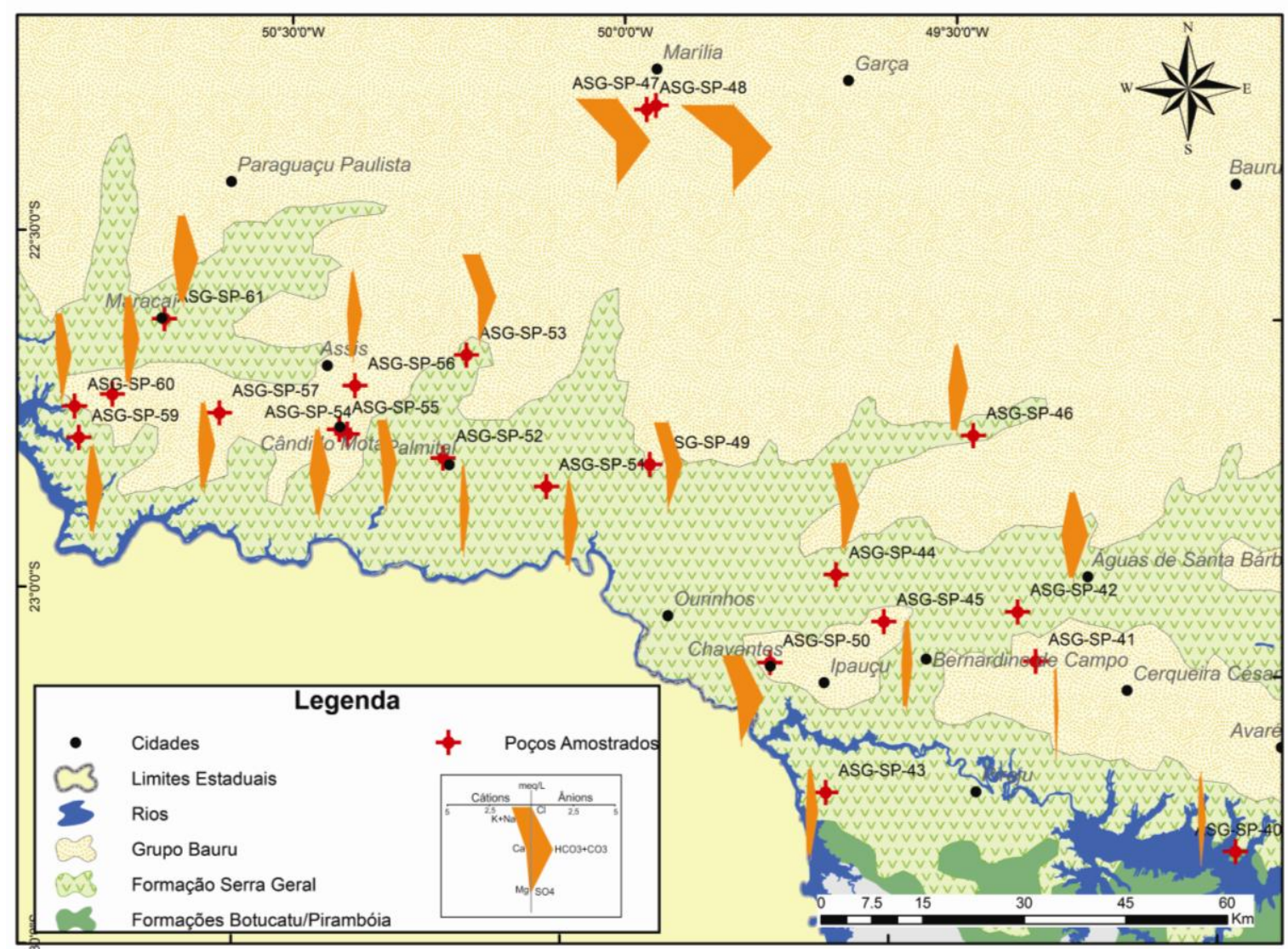

Figura 3 - Mapa de fácies hidroquímicas

Figure 3 - Hydrochemical facies map

A análise de agrupamentos é uma técnica estatística multivariada que utiliza a similaridade entre indivíduos de um grupo de amostras, para classificá-las hierarquicamente em grupos, considerando de maneira conjunta todas as variáveis determinadas para cada um dos indivíduos (DAVIS, 1986). Essa técnica é utilizada na identificação de grupos para o conjunto de amostras (Modo-Q) ou variáveis (Modo-R), e para sua aplicação não são necessários pré-requisitos, além do fato de que o conjunto de dados deve ser heterogêneo e que as distribuições das variáveis sejam normais e apresentem igual variância (GÜLLER et al., 2002). Como forma de se alcançar essa premissa, os dados foram normalizados e estandardizados.

Para a realização da análise de agrupamento, foram consideradas variáveis as concentrações de sódio, potássio, cálcio, magnésio, bicarbonato, carbonato, cloreto, sulfato, nitrato, fluoreto e sílica, o grau de similaridade determinado pelo coeficiente de distância euclidiana e o agrupamento pela média não ponderada.

A análise de agrupamento no Modo-R mostra a existência de quatro grupos de amostras (Figura 4). O grupo 1 é constituído pelas amostras que apresentam o menor grau de mineralização e coletadas nas cidades localizadas nas cabeceiras do Rio Pardo, no extremo leste da área de estudo (Amostras ASG-SP-40 e ASG-SP-41).

O grupo 2 compreende 15 amostras, cuja composição química é marcada pela presença do bicarbonato como ânion principal e cujas relações catiônicas indicam a preponderância de cálcio e sódio sobre os outros cátions. Esse grupo de amostras pode ser subdividido em dois subgrupos, que se diferenciam pelas concentrações de nitrato, maiores nas amostras do subgrupo $2 \mathrm{~B}$, indicando a ação antrópica sobre a composição química das águas subterrâneas.

As amostras do grupo 3 são àquelas que apresentam $\mathrm{pH}$ superior a 8,3 , com concentrações de sódio muito superiores as de cálcio, enquanto nas amostras do grupo 4, coletadas na cidade de Marília, se distinguem de todos os outros grupos, por apresentarem maior salinização, expressa por maiores condutividades elétricas, sendo possível aventar uma origem distinta para essas águas, não relacionada a interação com os basaltos, uma vez que é possível, fisicamente, a ascensão de águas provenientes do SAG (Figura 1). Deve-se considerar que as águas do SAG em sua zona de confinamento no estado de São Paulo, apresentam essa composição química e condutividades elétricas semelhantes (GASTMANS et al., 2010). 


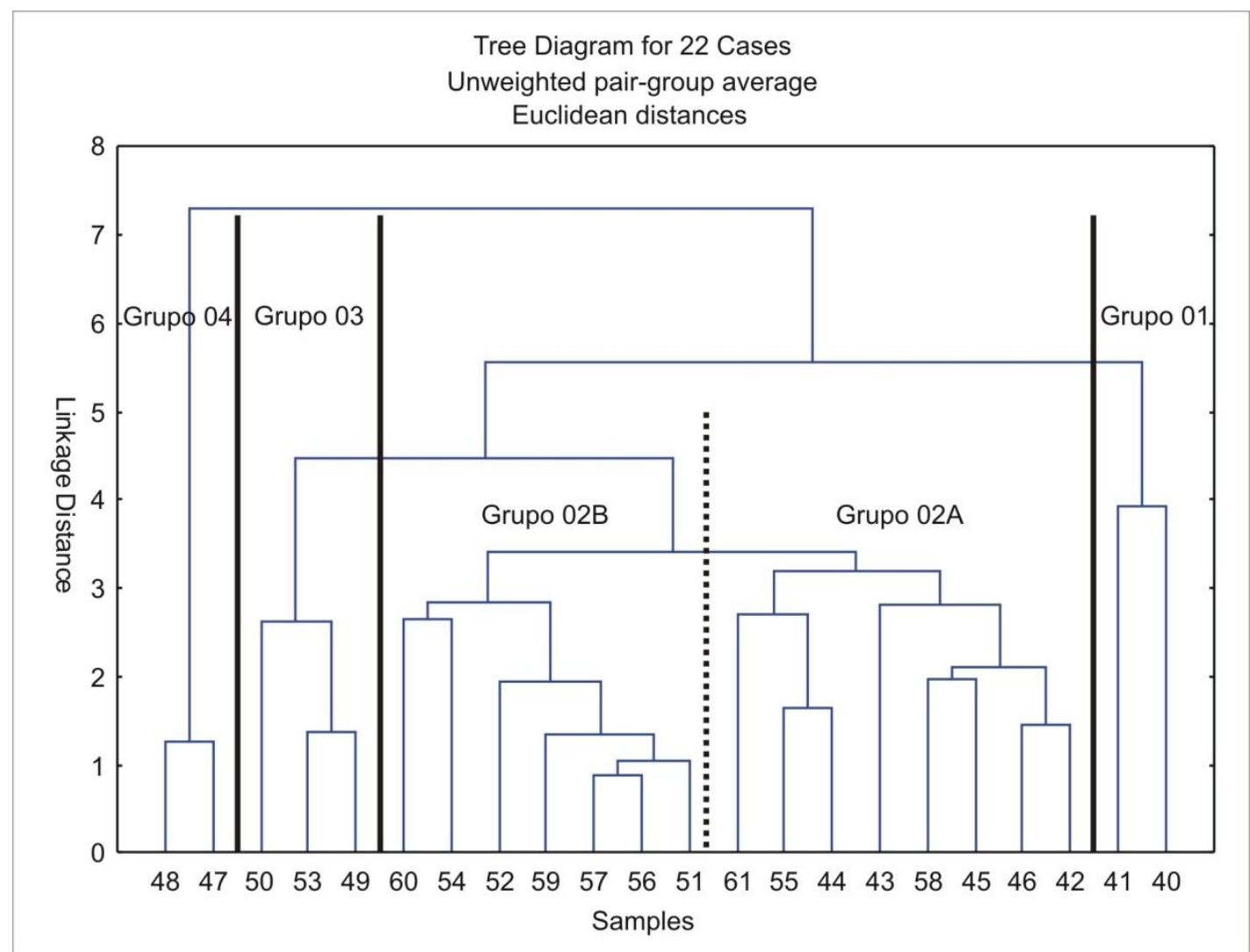

Figura 4 - Dendograma gerado a partir da Análise de Agrupamento Modo-Q

Figure 4 - Dendogram generated through Cluster Analisys - Q Mode

A análise das componentes emprega uma série de transformações matemáticas, sendo capaz de reduzir o número de variáveis em uma matriz de dados, por meio da combinação linear de uma ou mais variáveis, de modo a selecionar os parâmetros que distinguem as amostras, e que são capazes de explicar a variabilidade observada nessa matriz (DAVIS, 1986). Na avaliação dos resultados foi efetuada a rotação dos dados pelo método Varimax, que maximiza a variabilidade nos fatores, mantendo a ortogonalidade entre os fatores, auxiliando na redução da contribuição das variáveis com menor significância.

A aplicação do método descrito acima, aponta para a existência de 4 fatores responsáveis por explicar aproximadamente $92 \%$ da variância observada no grupo de amostras (Tabela 2).

Os escores para cada um dos fatores indicam os processos químicos descritos pelas componentes principais. O Fator 1 é responsável por quase $50 \%$ da variância observada, sendo influenciado essencialmente pelas concentrações de car- bonato, sódio, fluoreto e sulfato, enquanto o Fator 2 pelas concentrações de cloreto e nitrato.

Os processos responsáveis por esses dois fatores, estão associados à possível ascensão de águas do SAG, sotoposto, ricas nesses elementos, enquanto o segundo fator tem forte componente relacionada à ação antrópica, associada à contaminação das águas subterrâneas por nitrato, possivelmente proveniente dos sistemas de esgotamento sanitário dos municípios onde foram coletadas as amostras.

A análise dos escores dos fatores 1 e 2 para as amostras (Figura 5), mostra claramente a influência desses processos geoquímicos na distinção do grupo de amostras. As amostras provenientes dos poços da cidade de Marília apresentam altos escores para o Fator 1, enquanto as amostras em que são observadas as maiores concentrações de nitrato, possuem altos escores para o Fator 2. Já as amostras com baixas concentrações de nitrato, sódio e sem carbonato, possuem baixos escores para os fatores 1 e 2 . 
Tabela 2 - Resultados da Análise das Componentes Principais

Table 2 - Results of Principal Component Analisys

\begin{tabular}{cccccc}
\hline & Fator $\mathbf{1}$ & Fator $\mathbf{2}$ & Fator 3 & Fator 4 & Fator 5 \\
\hline $\mathbf{H C O}_{\mathbf{3}}$ & 0,088 & 0,141 & 0,186 & 0,332 & $\mathbf{0 , 9 0 7}$ \\
$\mathbf{C O}_{\mathbf{3}}$ & $\mathbf{0 , 8 5 1}$ & $-0,387$ & 0,139 & 0,041 & 0,126 \\
$\mathbf{N a}$ & $\mathbf{0 , 7 6 3}$ & $-0,064$ & 0,396 & $-0,030$ & 0,458 \\
$\mathbf{K}$ & $-0,204$ & 0,049 & $\mathbf{- 0 , 9 6 1}$ & $-0,008$ & $-0,169$ \\
$\mathbf{F}$ & $\mathbf{0 , 9 5 2}$ & $-0,207$ & 0,124 & 0,036 & 0,034 \\
$\mathbf{C l}$ & $-0,034$ & $\mathbf{0 , 9 4 4}$ & $-0,081$ & 0,240 & 0,154 \\
$\mathbf{N O}_{\mathbf{3}}$ & $-0,302$ & $\mathbf{0 , 9 3 4}$ & 0,018 & 0,009 & 0,001 \\
$\mathbf{S O}_{\mathbf{4}}$ & $\mathbf{0 , 9 2 6}$ & 0,052 & 0,060 & 0,068 & 0,011 \\
$\mathbf{C a}$ & $-0,677$ & 0,431 & $-0,134$ & 0,290 & 0,189 \\
$\mathbf{M g}$ & $-0,514$ & 0,475 & $-0,340$ & 0,426 & 0,006 \\
$\mathbf{S i}$ & 0,068 & 0,171 & 0,016 & $\mathbf{0 , 9 3 7}$ & 0,286 \\
Eighenvalue & 5,412 & 2,646 & 1,074 & 0,969 & 0,395 \\
Variância fator (\%) & 49,206 & 24,058 & 9,771 & 8,809 & 3,597 \\
Variância Acumulada (\%) & 49,206 & 73,264 & 83,035 & 91,844 & 95,442 \\
\hline Obs.: Valo
\end{tabular}

Obs.: Valores anotados em negrito indicam os escores para as variáveis mais importantes na composição dos fatores.

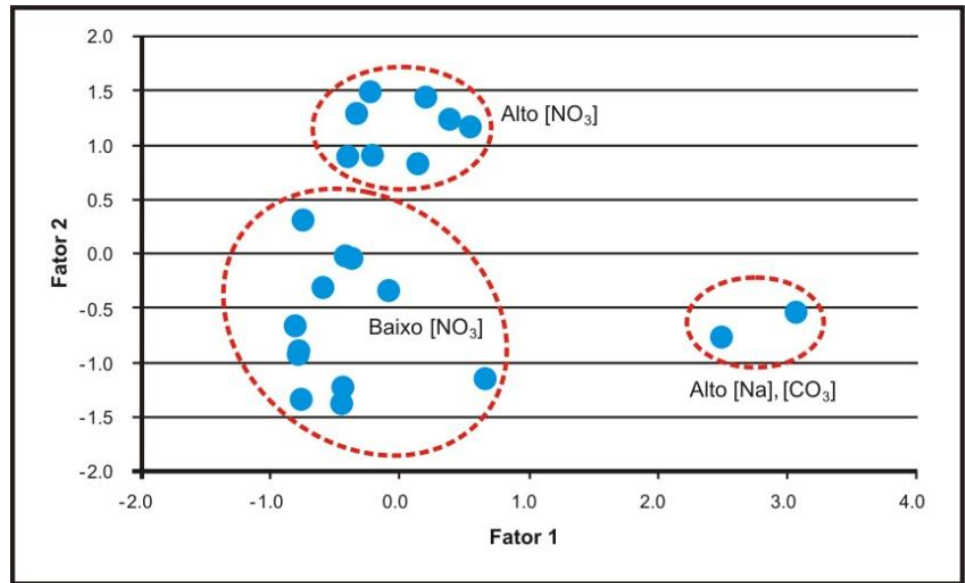

Figura 5 - Escores de fatores 1 e 2 para as amostras, mostrando a distinção dos grupos de amostras em função dos processos geoquímicos

Figure 5 - Eighenvalues scores for factors 1 and 2, showing the diferentiation of the samples groups due to geochemical processes

\section{Modelo Geoquímico Conceitual}

A composição química das águas subterrâneas está associada a uma série de processos e reações geoquímicas naturais, relacionados à interação água-rocha, incluindo a produção de ácido carbônico, a dissolução mineral, reações de oxiredução, precipitação de minerais, reações de troca iônica e adsorção de elementos, dentre outros (HEM, 1985). Em aquíferos basálticos a interação água-rocha pode ser sumarizada pela reação abaixo, em que os cátions e o bicarbonato são adicionados à água pela dissolução de minerais pré existentes, com a formação de novos minerais, especialmente alumino-silicatos (caolinitas e smectitas) (DAFNY et al., 2006).
BASALTO $+\mathrm{CO}_{2}+\mathrm{H}_{2} \mathrm{O} \rightarrow$ Al-Si-Minerais +

A avaliação dessa reação deixa implícita a existência de correlação entre as concentrações dos principais cátions com a alcalinidade, entretanto o que se observa, no caso das amostras analisadas, é que existe uma boa correlação entre o cálcio e a alcalinidade nas águas com menor concentração nesses constituintes, com o aumento da alcalinidade a concentração de cálcio diminui (Figura 06A). Um comportamento distinto é observado na relação entre a alcalinidade e o sódio, 
observa-se uma boa correlação entre as concentrações de sódio e a alcalinidade nas amostras que apresentam as maiores concentrações desses compostos (Figura 06B), entretanto deve ser observado que existe uma descontinuidade no enriquecimento de sódio, para se alcançar as amostras com maior concentração nesse elemento, indicando dois possíveis processos: uma delas associada a dissolução de minerais ricos em sódio e/ou processos de troca iônica, para as amostras menos enriquecidas, coletadas na porção centro sul da área, ambos associados a evolução das águas subterrâneas, e um segundo associado a contaminação por águas provenientes do SAG, especificamente na cidade de Marília.

Esse comportamento distinto, das concentrações de sódio e cálcio frente à alcalinidade, faz com que seja observado o aumento das concentrações de sódio frente à diminuição das concentrações de cálcio, em uma relação praticamente exponencial (Figura 06E).

Apesar da pequena correlação observada entre a alcalinidade e as concentrações de magnésio (Figura 06C), pode-se inferir comportamento semelhante ao do cálcio, uma vez que existe uma boa correlação entre as concentrações dos dois elementos (Figura 06D).

As concentrações de cloreto e nitrato possuem boa correlação (Figura 076), reforçando origem antrópica para esses compostos, conforme já demonstrado por meio da análise estatística, uma vez que não relatadas possíveis fontes naturais de nitrato em rochas basálticas.

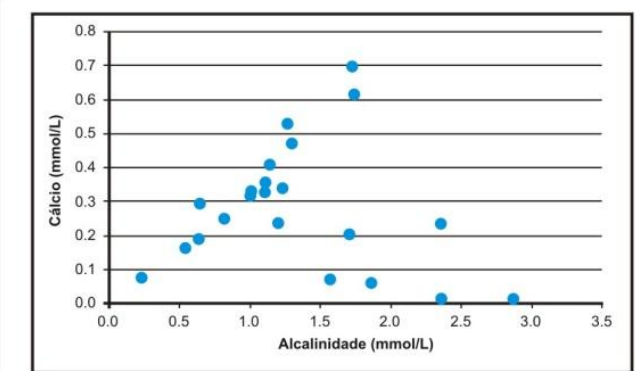

A

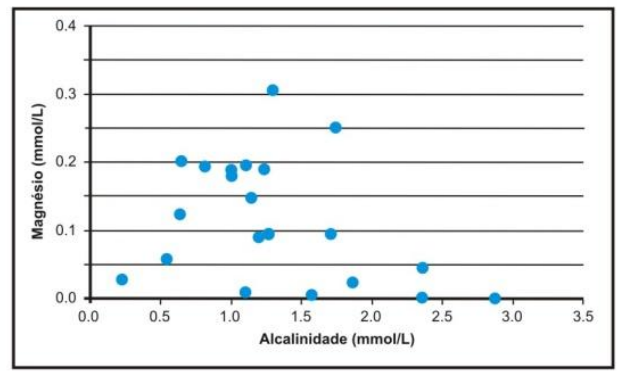

C

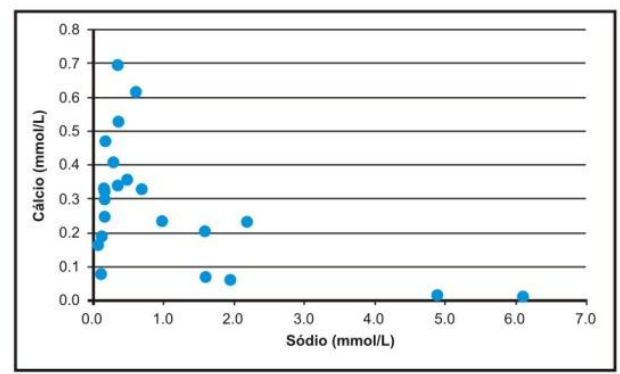

E

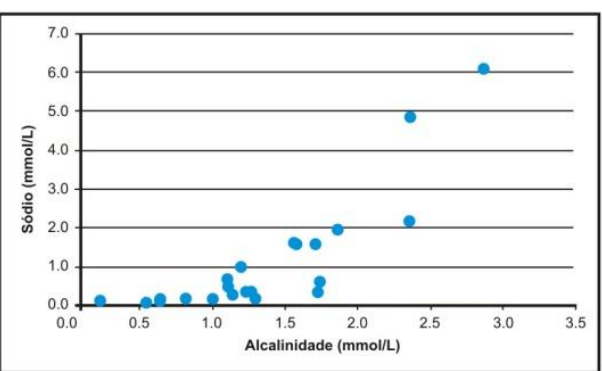

B

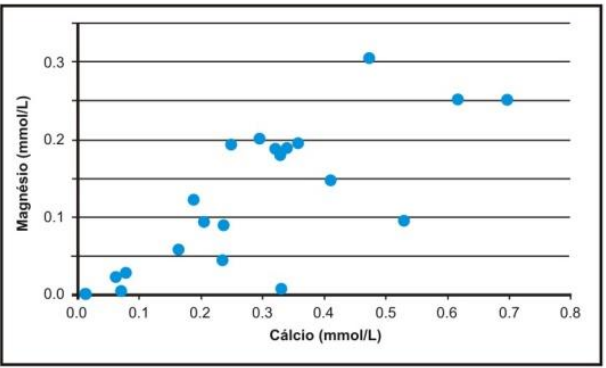

D

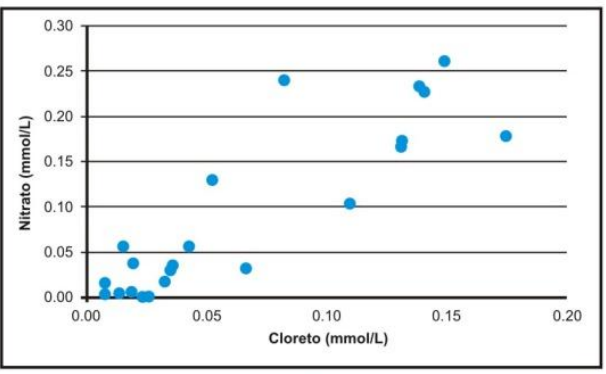

$\mathbf{F}$

Figura 6 - Gráficos de correlação entre: (A) Cálcio x Alcalinidade; (B) Sódio x Alcalinidade; (C) Magnésio x Alcalinidade; (D) Magnésio x Cálcio; (E) Sódio x Cálcio; (F) Cloreto x Nitrato

Figure 6 - Scare plots showing the relationship between: (A) Calcium x Alcalinity (B) Sodium $x$ Alcalinity; (C) Magnesium x Alcalinity; (D) Magnesium x Calcium; (E) Sodium x Calcium; (F) Chloride x Nitrate 
Foram calculados os índices de saturação para algumas espécies minerais presentes na assembleia mineralógica dos basaltos especialmente nas zonas interderrames e de ocorrência de bre- chas por Janasi et al. (2007) e Machado et al. (2007), dentre outros, com a utilização do software PhreeqC (PARKHURST \& APELLO, 1999), apresentados na tabela 3 .

Tabela 3 - Indíces de Saturação

Table 3 - Saturation Index

\begin{tabular}{|c|c|c|c|c|}
\hline Código Amostra & ISat_Calcita & ISat_Calcedônia & ISat_Dolomita & ISat_Fluorita \\
\hline ASG-SP-40 & $-2,5977$ & $-0,1469$ & $-5,5331$ & $-4,4160$ \\
\hline ASG-SP-41 & $-2,5894$ & $-0,3753$ & $-5,4940$ & $-4,7320$ \\
\hline ASG-SP-42 & 0,0465 & 0,1613 & $-0,2364$ & $-3,7118$ \\
\hline ASG-SP-43 & $-1,8829$ & $-0,0176$ & $-3,7724$ & $-4,1562$ \\
\hline ASG-SP-44 & $-0,6626$ & 0,0096 & $-1,5410$ & $-4,0501$ \\
\hline ASG-SP-45 & $-2,3081$ & 0,1074 & $-4,6693$ & $-4,1016$ \\
\hline ASG-SP-46 & $-0,8837$ & 0,1438 & $-1,8127$ & $-3,9402$ \\
\hline ASG-SP-47 & $-0,0924$ & $-0,5558$ & $-1,1480$ & $-4,0336$ \\
\hline ASG-SP-48 & $-0,0911$ & $-0,4177$ & $-1,4078$ & $-4,2812$ \\
\hline ASG-SP-49 & $-0,1560$ & $-0,0949$ & $-1,2692$ & $-4,4166$ \\
\hline ASG-SP-50 & 0,7469 & $-0,0909$ & 0,9678 & $-3,2498$ \\
\hline ASG-SP-51 & $-0,6652$ & 0,0635 & $-1,4351$ & $-4,3556$ \\
\hline ASG-SP-52 & $-1,5625$ & 0,0594 & $-3,1835$ & $-4,1983$ \\
\hline ASG-SP-53 & $-0,2653$ & $-0,0835$ & $-0,8221$ & $-4,1784$ \\
\hline ASG-SP-54 & $-0,8401$ & $-0,1160$ & $-2,2857$ & $-4,5002$ \\
\hline ASG-SP-55 & $-1,0194$ & $-0,0247$ & $-2,3236$ & $-3,2754$ \\
\hline ASG-SP-56 & $-0,7640$ & 0,1366 & $-1,6761$ & $-4,2488$ \\
\hline ASG-SP-57 & $-0,5686$ & 0,1268 & $-1,2762$ & $-4,2078$ \\
\hline ASG-SP-58 & $-1,1067$ & 0,1243 & $-2,3668$ & $-4,0915$ \\
\hline ASG-SP-59 & $-0,4167$ & 0,0890 & $-1,1548$ & $-3,8514$ \\
\hline ASG-SP-60 & $-0,0172$ & 0,0325 & $-1,5205$ & $-3,8153$ \\
\hline ASG-SP-61 & 0,0225 & 0,1161 & $-0,2073$ & $-3,6829$ \\
\hline
\end{tabular}

As águas subterrâneas apresentam-se em sua maior parte insaturadas em relação à calcita, apenas as amostras com maiores concentrações para a alcalinidade encontram-se saturadas ou próximas a saturação (Tabela 3 e Figura 7A). Observa-se a mesma tendência para a saturação em calcita em relação ao aumento das concentrações de cálcio, levando a precipitação desse mineral com consequente redução nas concentrações desse elemento, entretanto sem modificar a saturação em relação a esse mineral, uma vez que a elevação do $\mathrm{pH}$ controla esse processo (Figuras 7B e 7C).

A maior parte das amostras apresentam-se saturadas ou subsaturada em relação a calcedônia (Figura 7D), o que corrobora as observações feitas por Janasi et al. (2007) e Machado et al. (2007), dentre outros, relativas a presença de veios de sílica, preenchendo fraturas e cimentando zonas brechadas nos derrames basálticos. Existe uma relação de aumento nas concentrações de sílica confrontadas com o índice de saturação em calcedônia.

Todas as amostras apresentam-se insaturadas em relação à dolomita e a fluorita, à exceção feita a amostra ASG-SP-50 que apresenta-se saturada em relação a dolomita. Essas relações indicam que as concentrações de flúor advém da dissolução da fluorita, e que não deve ser encontrada dolomita preenchendo as vesículas e descontinuidades nas zonas brechadas dos contatos dos derrames.

Em relação aos silicatos, as águas subterrâneas estão em equilíbrio termodinâmico essencialmente com a caulinita (Figura 8), indicando que a dissolução dos minerais constituintes dos basaltos é incongruente. $\mathrm{O}$ sistema $\mathrm{CaO}-\mathrm{Al}_{2} \mathrm{O}_{3^{-}}$ $\mathrm{SiO}_{2}-\mathrm{H}_{2} \mathrm{O}$, indica que parte das amostras encontra-se em equilíbrio com a Montmorilonita-Ca, enquanto para o sistema $\mathrm{Na}_{2} \mathrm{O}-\mathrm{Al}_{2} \mathrm{O}_{3}-\mathrm{SiO}_{2}-\mathrm{H}_{2} \mathrm{O}$ a maior parte das amostras encontra-se em equilíbrio com a caolinita, pressupondo que a presença de argilo minerais que funcionariam como sítios de troca iônica, seja incipiente, ou mesmo inexistente. Os processos de troca iônica devem estar associados a presença de zeólitas preenchendo vesículas e amigdalas nas zonas interderrames, entretanto a comprovação desse processo necessita de maior investigação. 


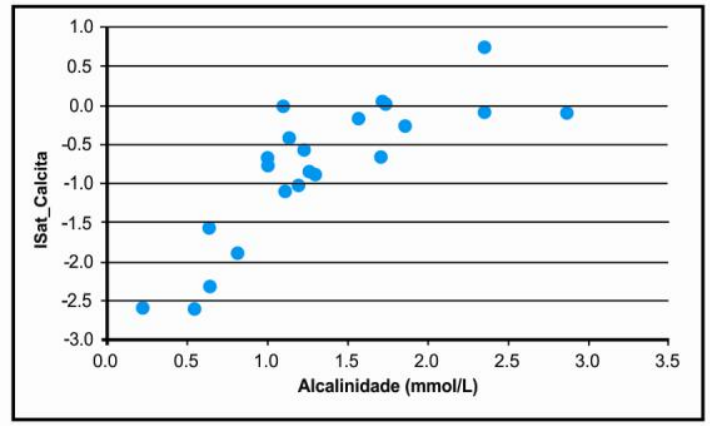

A

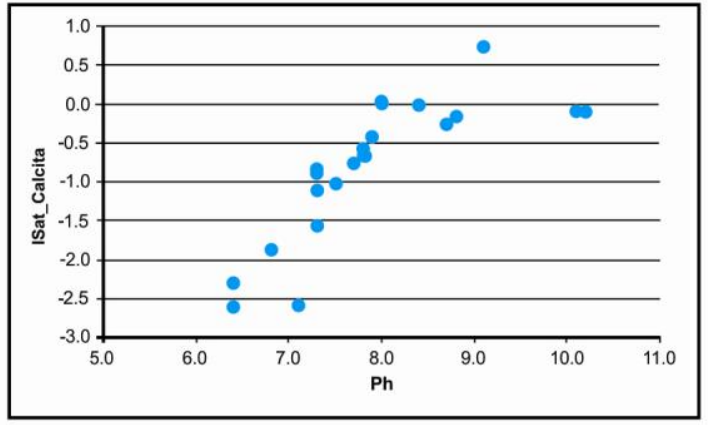

C

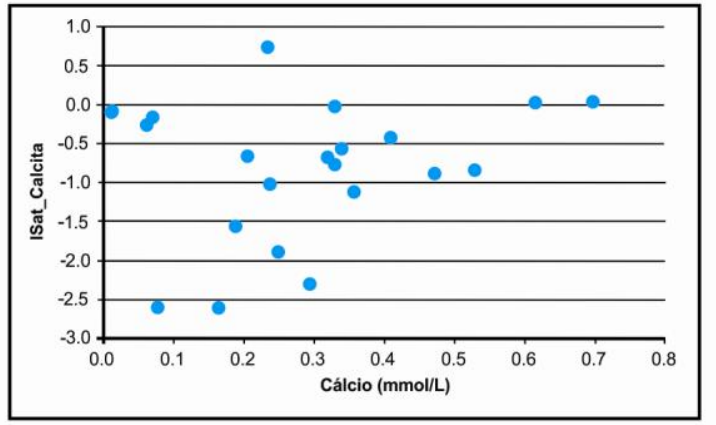

B

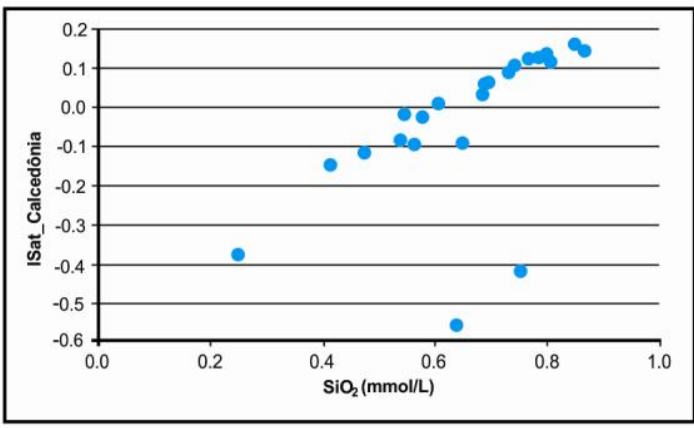

D

Figura 7 - Gráficos de correlação entre: (A) Alcalinidade x Índice de Saturação em Calcita; (B) Cálcio x Índice de Saturação em Calcita; (C) pH x Índice de Saturação em Calcita; (D) Sílica x Índice de Saturação em Quartzo

Figure 7 - Scare plots showing the relationship between: (A) Alcalinity x Saturation Index of Calcite (B) Calcium x Saturation Index of Calcite; (C) pH x Saturation Index of Calcite; (D) Silicon x Saturation Index of Quartz

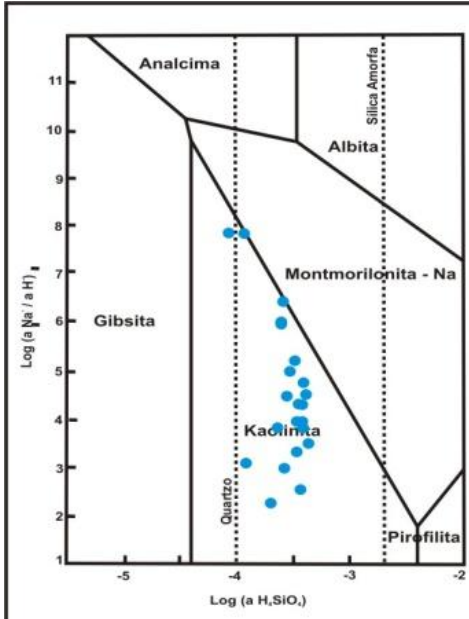

(A)

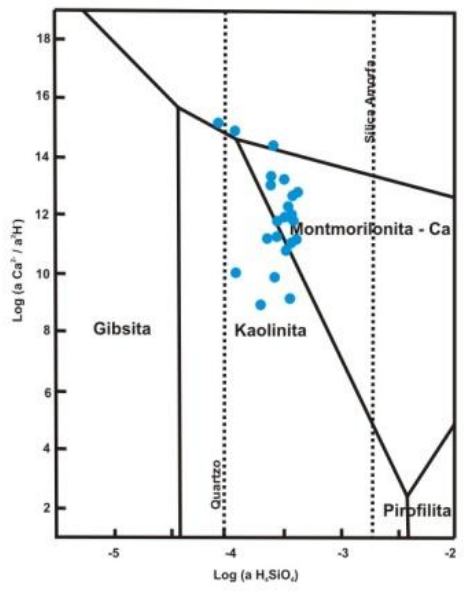

(B)

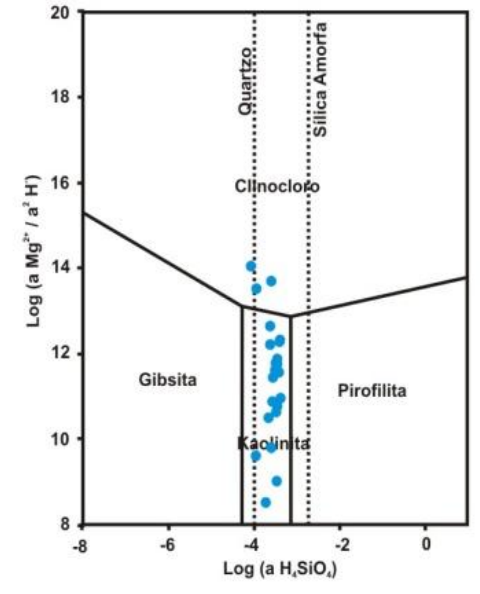

(C)

Figura 8 - Diagramas de estabilidade. (A) Sistema $\mathrm{Na}_{2} \mathrm{O}-\mathrm{Al}_{2} \mathrm{O}_{3}-\mathrm{SiO}_{2}-\mathrm{H}_{2} \mathrm{O}$; (B) Sistema CaO- $\mathrm{Al}_{2} \mathrm{O}_{3}-\mathrm{SiO}_{2}-\mathrm{H}_{2} \mathrm{O}$; (C) Sistema $\mathrm{MgO}-\mathrm{Al}_{2} \mathrm{O}_{3}-\mathrm{SiO}_{2}-\mathrm{H}_{2} \mathrm{O}$

Figure 8 - Stability Diagrams. (A) System $\mathrm{Na}_{2} \mathrm{O}-\mathrm{Al}_{2} \mathrm{O}_{3}-\mathrm{SiO}_{2}-\mathrm{H}_{2} \mathrm{O}$; (B) System $\mathrm{CaO}-\mathrm{Al}_{2} \mathrm{O}_{3}-\mathrm{SiO}_{2}-\mathrm{H}_{2} \mathrm{O}$; (C) System $\mathrm{MgO}-\mathrm{Al}_{2} \mathrm{O}_{3}-\mathrm{SiO}_{2}-\mathrm{H}_{2} \mathrm{O}$

Outro processo associado ao aumento exponencial observado nas concentrações de sódio, parece estar relacionado à saturação em calcita, que retiraria o cálcio das águas subterrâneas, por meio da precipitação desse mineral, fazendo com que processos de troca iônica relacionado a presença de zeólitas e/ou argilo minerais retire o cálcio não precipitado sob a forma de carbonatos, 
e libere o sódio para as águas subterrâneas. Esse processo deve ser acompanhado do fornecimento de $\mathrm{CO}_{2}$ para que as reações de dissolução possam ocorrer, isso é corroborado essencialmente pelo aumento constante da alcalinidade e do $\mathrm{pH}$ das águas subterrâneas (Figura 9).

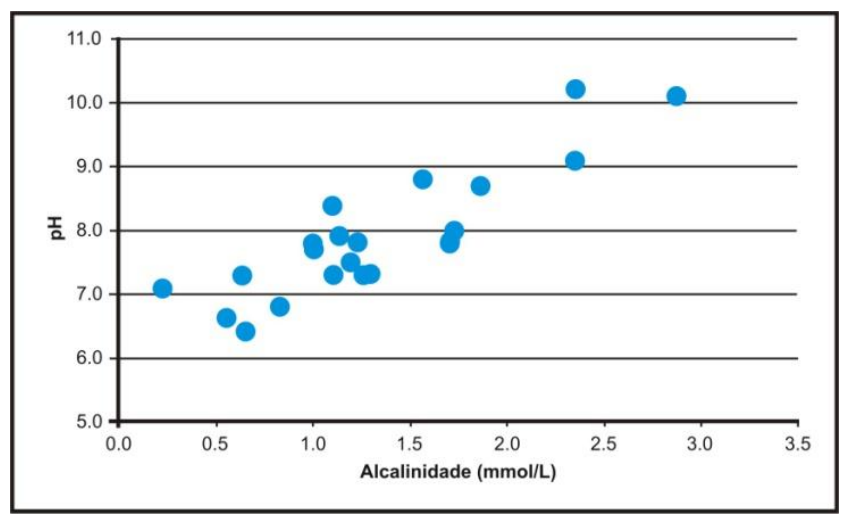

Figura 9 - Correlação entre a alcalinidade e o pH das amostras de águas do ASG na área de estudo Figure 9 - Relationship between alkalinity and pH observed on groundwater collected samples of the SGA

\section{CONCLUSÕES}

As águas subterrâneas do ASG na área de estudo em sua grande maioria apresentam baixa mineralização, com condutividades elétricas geralmente inferiores a $200 \mu \mathrm{S} / \mathrm{cm}$, com pH's geralmente próximos a neutralidade, mas que podem alcançar valores superiores a 10 , observados nas amostras coletadas na cidade de Marília.

A composição dessas águas, em sua maioria do tipo $\mathrm{Ca}-\mathrm{Mg}-\mathrm{HCO}_{3}$ e $\mathrm{Na}-\mathrm{HCO}_{3}$, está associada a processos de dissolução dos minerais constituintes das rochas, que leva a saturação em calcita, observada em algumas amostras.

Esse processo de dissolução constante dos minerais das rochas basálticas, especialmente nas áreas em que os basaltos não estão sobrepostos aos arenitos do Grupo Bauru, está associado a um sistema aberto ao $\mathrm{CO}_{2}$, comprovado pelo aumento do linear observado entre o $\mathrm{pH}$ e a alcalinidade.

Quando é alcançada a saturação em calcita, consequentemente são observadas diminuições das concentrações de cálcio, e aumento nas con- centrações de sódio. Esse fenômeno possivelmente está associado a processos de troca iônica, corroborado pela presença de zeólitas nas zonas interderrames, ou em menor escala relacionado a algum argilo mineral gerado pela dissolução de plagioclásios sódicos.

As águas mais salinizadas, coletadas na cidade de Marília, apresentam concentrações de sódio, alcalinidade e valores de $\mathrm{pH}$, semelhantes aos observados nas águas do SAG, corroborado pela possibilidade hidráulica de fluxos ascendentes

A aplicação de técnicas estatísticas multivariadas auxiliou na identificação da importância da ação antrópica sobre a qualidade das águas subterrâneas do ASG na área, tornando-se fator responsável pela diferenciação entre os grupos de amostras. Apesar das concentrações não alcançarem os valores de referência para sua potabilidade, ações para a conservação da qualidade do recurso devem ser imediatamente tomadas.

\section{AGRADECIMENTOS}

O autor agradece a FAPESP pelo auxílio concedido (Projeto FAPESP $n^{\circ}$ 2012/00241-5), que possibilitou a realização deste estudo, e aos dois revisores anônimos que, por meio de suas sugestões, contribuíram para o aprimoramento das discussões dos resultados.

\section{REFERÊNCIAS}

BARISON, M.R. Estudo Hidroquímico na Porção Meridional do Sistema Aquífero Bauru no Estado de São Paulo. 153p, Tese (Doutorado em Geociências e
Meio Ambiente) Instituto de Geociências e Ciências Exatas, UNESP, Rio Claro (SP), 2003. 
BELLIENI, G.; COMIN-CHIAROMONTI, P.; MARQUES, L.S.; MELFI, A.J.; NARDY, A.J.; PAPATRECHAS, C.; PICCIRILO, E.M.; ROISEMBERG, A. Petrogenetic Aspects of Acid and Basaltic Lavas from the Paraná Plateau (Brazil): Geological, Mineralogical and Petrochemical Relationships. Journal of Petrology, v,27, p.915-944. 1986.

BITTENCOURT, A.V.L. Sobre o Controle do Quimismo de Águas Termais da Bacia do Paraná. Boletim Paranaense de Geociências. v, 44, p.117-129. 1996.

BITTENCOURT, A.V.L.; ROSA FILHO E.F.; HINDI E.C.; BUCHMANN FILHO A. C. A Influência dos Basaltos e de Misturas com Águas de Aquíferos Sotopostos nas Águas Subterrâneas do Sistema Aquífero Serra Geral na Bacia do Rio Piquiri, Paraná - BR. Revista Águas Subterrâneas. v.17, p.67-75, 2003.

BOFF, F.E.; MEDEIROS, M.A.; MULLER, A.L.; KOPPE, J.C. Caracterização Hidroquímica das Águas Minerais da Serra do Nordeste Gaúcho. In: Congresso Brasileiro de Águas Subterrâneas, 14. 2006. CDROOM,,,Curitiba:ABAS. 2006. 18p.

BRASIL Ministério da Saúde Portaria MS Portaria 2914/2011 de 12 de dezembro de 2011, disponível no site:

http://bvsms.saude.gov.br/bvs/saudelegis/gm/2011/prt291 41212 2011.html. acessado em 17 de junho de 2013

BUCHMANN FILHO, A.C.; ROSA FILHO E.F.; HINDI E.C.; BITTENCOURT, A.V.L.; NADAL, C.A.; FERREIRA, F.J.F. Aspectos da Química da Água Subterrânea da Formação Serra Geral no Âmbito da Bacia Hidrográfica do Rio Piqueri (PR). In: Congresso Brasileiro de Águas Subterrâneas, 12. 2002. CD-ROOM.... Florianópolis:ABAS. 2002. 17p.

CAMPOS, H.C.N.S. Contribuição ao Estudo Hidrogeoquimico do Grupo Bauru no Estado de São Paulo. 105p. Dissertação de Mestrado, Instituto de GeociênciasUniversidade de São Paulo. São Paulo (SP), 1987.

CAMPOS, H.C.N.S. Caracterização e Cartografia das Províncias Hidrogeoquímicas do Estado de São Paulo. 177p. Tese de Doutoramento, Instituto de GeociênciasUniversidade de São Paulo. São Paulo (SP). 1993.

CPTI - Cooperativa de Serviços e Pesquisas Tecnológicas e Industriais. Primeiro Relatório de Situação dos Recursos Hídricos da UGRHI-17 ("Relatório Zero"), CIERGA Assis. 362 p. 1999.

DAFNY, E.; BURG, A.; GVIRTZMAN, H. Deduction of Groundwater Flow Regime in a Basaltic Aquifer Using Geochemical and Isotopic Data: The Golan Heights, Israel Case Study. Journal of Hydrology. v. 330, p. 506524. 2006.

DAVIS, J.C. Statistics and Data Analisys in Geology. Toronto: John Wyley \& Sons.

DECKART, K.; FÉRAUD, G.; MARQUES, L.S.; BERTRAND, H. New Time Constraints on Dyke Swarms Related to the Paraná-Etendeka Magmatic Province, and Subsequent South America Opening Southeastern Brazil. Journal of Volcanology and Geothermal Research. v.80, p. 67-83. 1998.
DEPARTAMENTO DE ÁGUAS E ENERGIA ELÉTRICA DO ESTADO DE SÃO PAULO. Estudo de Águas Subterrâneas, Região Administrativa 6 - Ribeirão Preto, São Paulo: DAEE. 1974. Volume 2. (Texto).

DEPARTAMENTO DE ÁGUAS E ENERGIA ELÉTRICA DO ESTADO DE SÃO PAULO Estudos de Água Subterrânea - Regiões Administrativas 7, 8, 9 (Bauru, São José do Rio Preto, Araçatuba). São Paulo: DAEE. 1976. Volume 2. 286p. (Texto).

DEOLANKAR, S.B. The Deccan Basalts of Maharashtra, India - Their Potential as Aquifers. Ground Water. v18(5), p.434-437. 1980.

DEUTSCH, W.J.; JENNE, E.A.; KRUPKA, K.M. Solubility Equilibria in Basalt Aquifers: The Columbia Plateau, Eastern Washington, USA. Chemical Geology. v36, p. 15-34. 1982.

DOMENICO, P.A.; SCHWARTZ, F.W. Physical and Chemical Hydrogeology. New York: John Wiley \& Sons. 1998. 824p.

DREVER, J.I. The Geochemistry of Natural Waters, Surface and Groundwater Environment. $3^{\text {rd }}$ edition. Prentice Hall, Upper Saddle River, NJ. 436p. 1997.

ERNESTO, M.; RAPOSO, M.I.B.; MARQUES, L.S.; RENNE, P.R.; DIOGO, L.A.; DE MIN, A. Paleomagnetism, geochemistry and ${ }^{40} \mathrm{Ar} /{ }^{39} \mathrm{Ar}$ Dating of the Northeastern Paraná Magmatic Province: Tectonic Implications. Journal of Geodynamics. v.28, p. 321-340. 1999.

FERNANDES, A.; MALDANER, C.H.; ROULEAU, A. Análise das Fraturas nos Basaltos de Ribeirão Preto, SP: Aplicação à Elaboração de Modelo Hidrogeológico Conceitual. In: Congresso Brasileiro de Águas Subterrâneas, 16. 2010. CD-ROOM.... São Luis:ABAS. 2010. 20p.

GALLO, G., SINELLI, O. Estudo Hidroquímico e Isotópico das Águas Subterrâneas na Região de Ribeirão Preto (SP). Revista Brasileira de Geociências. v.10, p. 129140. 1980.

GASTMANS, D.; CHANG, H. K.; HUTCHEON, I. Groundwater Geochemical Evolution in the Northern Portion of the Guarani Aquifer System (Brazil) and its relationship to diagenetic features. Applied Geochemistry. v,25, p. 16-33. 2010.

GASTMANS, D.; CHANG, H.K. Circulação das Águas Subterrâneas do Sistema Aquífero Guarani nas Proximidades da Zona de Afloramentos no Estado de São Paulo. In: Congresso Brasileiro de Águas Subterrâneas, 17. 2012. CD-ROOM.... Bonito: ABAS. 2012. 4p.

GÜLLER, C.; THYNE, G.D.; McCRAY, J.E.; TURNER, A.K. Evaluation of Graphical and Multivariate Statistical Methods for Classification of Water Chemistry Data. Hydrogeology Journal. v.10, p.455-474. 2002.

IRAWAN, D.E.; PURADIMAJA, D.J.; NOTOSISWOYO, S.; SOEMINTADIREJA, P. Hydrogeochemistry of Volcanic Hydrogeology Based on Cluster Analysis of Mountain Ciremai, West Java, Indonesia. Journal of Hydrology. v.376, p. 221-234. 2009. 
JANASI, V.A.; MONTANHEIRO, T.J.; FREITAS, V.A.; REIS, P.M.; NEGRI, F.A.; DANTAS, F.A. Geology, Petrography and Geochemistry of the Acid Volcanism of the Paraná Magmatic Province in the Piraju-Ourinhos Region, SE Brazil. Revista Brasileira de Geociências. v.37(4), p. 745-759. 2007.

KIMMELMANN e SILVA, A.A.; SILVA, R.B.G.; REBOUÇAS, A.C.; SANTIAGO, M.M.F. Hidrologia Isotópica do Aqüífero Botucatu - Bacia do Paraná - Brasil. In: CONGRESSO BRASILEIRO DE HIDROGEOLOGIA, 4. 1986. Brasília. Anais..... Brasília: ABAS. 1986. p. 125.

LASTORIA, G. Hidrogeologia da Formação Serra Geral no Estado de Mato Grosso do Sul. 2002. 197p. Tese (Doutorado em Geociências e Meio Ambiente) Instituto de Geociências e Ciências Exatas. Universidade Estadual Paulista, Rio Claro. 2002.

LASTORIA, G.; SINELLI, O.; CHANG, H. K.; HUTCHEON, I.; PARANHOS FILHO, A. C.; GASTMANS, D. Hidrogeologia da Formação Serra Geral no Estado de Mato Grosso do Sul. Águas Subterrâneas. v.20, p. 139150. 2006.

LÉONARDI, V.; ARTHAUD, F.; GRILLOT, J.C.; AVETISSIAN, V.; BOCHNAGHIAN, P. Modélisation d'un Aquifère Basaltique Fracturé Tenant Comptes de Données Géologiques, Climatiques et Hydrauliques: Cas de Basaltes Perchés de Garni (Arménie). Journal of Hydrology. v.179, p. 87-109. 1996.

LOCSEY, K.L.; COX, M.E. Statistical and Hydrochemical Methods to Compare Basalt and Basement Rock Hosted Groundwaters: Atherton Tablelands, Northeastern Australia. Environmental Geology. v.43, p. 698-713. 2003.

MACHADO, F.B.; NARDY, A.J.R.; OLIVEIRA, M.A.F. Geologia e Aspectos Petrológicos das Rochas Intrusivas e Efusivas Mesozóicas de Parte da Borda Leste da Bacia do Paraná no Estado de São Paulo. Revista Brasileira de Geociências. v.37(1), p. 64-80. 2007.

MACHADO, J.L.F.; FREITAS, M.A.; CAYE, B.R. Evolução Hidrogeoquímica dos Aquíferos no Oeste Catarinense. In: Congresso Brasileiro de Águas Subterrâneas, 12. 2002. CD-ROOM.... Florianópolis:ABAS. 2002. 10p.

MANASSES, F.; ROSA FILHO, E.F.; BITTENCOURT, A.V.L. Estudo Hidrogeoquímico da Formação Serra Geral na Região Sudoeste do Estado do Paraná. Revista Brasileira de Águas Subterrâneas. v.21(2), p.49-58. 2007.

MENG, S.X.; MAYNARD, J.B. Use of Statistical Analysis to Formulate Conceptual Models of Geochemical Behavoir: Water Chemical Data From the Botucatu Aquifer in São Paulo State, Brazil. Journal of Hydrology. v. 250, p. 78-87. 2001.

MILANI, E.J.; FRANÇA, A.B.; SCHNEIDER, R.L. Bacia do Paraná. Boletim de Geociências da Petrobrás. v. $8, \mathrm{n}^{\circ} 1$, p. 69-82. 1994.

NANNI, A.S. O Flúor em Águas do Sistema Aquífero Serra Geral no Rio Grande do Sul: Origem e Condi- cionamento Geológico. 2008, 127p. Tese de Doutorado, Instituto de Geociências, Universidade Federal do Rio Grande do Sul, Porto Alegre. 2008.

NARDY, A.J.R.; OLIVEIRA, M.A.F.; BETANCOURT, R.H.S.; VERDUGO, D.R.H.; MACHADO, F.B. Geologia e Estratigrafia da Formação Serra Geral. Revista Geociências. v. 21(2), p. 15-32. 2002.

OYEBOG, S.A.; AKO, A.A.; NKENG, G.E.; SUH, E.C. Hydrochemical Characteristics of some Cameron Bottled Waters, Investigated by Multivariate Statistical Analyses. Journal of Geochemical Exploration. v.112, p. 118130. 2012.

PARKHURST, D.L.; APPELO, P. User's guide to PHREEQC (Version 2) - A computer program for speciation, speciation, batch-reaction, onedimensional transport, and inverse geochemical calculations: Denver: USGS, 1999. 310p. U.S. Geological Survey Water-Resources Investigations Report 99-4259.

PAULA e SILVA, F.S.; CHANG, H. K.; CAETANOCHANG, M.R. Hidroestratigrafia do Grupo Bauru (K) no Estado de São Paulo. Águas Subterrâneas. v.19(2), p. 19-36. 2005.

PERRONI, J.C.A.; SILVA, R.B.G.; HIRATA, R.C.A.; DOZZI, L.F.S.; Ocorrências de Fluoreto nos Aquíferos da Bacia do Paraná no Estado de São Paulo. In: Simpósio Regional de Geologia, 5, 1985. Atas..... São Paulo, SBG. 1985. v.2, p. 503-514.

REBOUÇAS, A. C. Sistema Aquífero Botucatu no Brasil. In: CONGRESSO BRASILEIRO DE ÁGUAS SUBTERRÂNEAS, 8, Recife. Anais..... Recife, 1994, p.500509.

REBOUÇAS, A.C.; FRAGA, C.G. Hidrogeologia das rochas vulcânicas do Brasil. Revista Brasileira de Águas Subterrâneas. v.12, p.29-55. 1988.

ROSA FILHO, E.F.; BITTENCOURT, A.V.L.; HINDI, E.C.; BITTENCOURT, A. Estudo sobre os tipos de águas e as condicionantes estruturais do Sistema Aquífero Guarani no extremo oeste do Paraná. Revista Brasileira de Águas Subterrâneas. v.20(2), p.39-48. 2006.

SILVA, R.B.G. Estudo Hidroquímico e Isotópico do Aquífero Botucatu no Estado de São Paulo. 1983, 133p. Tese (Doutorado em Geologia) - Instituto de Geociências - Universidade de São Paulo. São Paulo. 1983.

SRACEK, O.; HIRATA, R. Geochemical and Stable Isotopic Evolution of the Guarani Aquifer System in the State of São Paulo, Brazil. Hydrogeology Journal. v.10, p. 643-655. 2002.

SUK, H., LEE, K.K. Characterization of a Ground Water Hydrochemical System Through Multivariate Analysis: Clustering into Ground Water Zones. Ground Water. v. 37(3), p. 358-366. 1999.

USUNOFF, E.J.; GUZMAN-GUZMAN, A. Multivariate Analysis in Hydrochemistry: an Example of the Use of Factor and Correspondence Analyses. Ground Water. v. 27(1), p,27-34. 1989.

VIDAL, A.C.; KIANG, C.H. Caracterização Hidroquími- 
ca dos Aquíferos da Bacia de Taubaté. Revista Brasileira de Geociências. v. 32(2), p. 267-276. 2002.

WAHNFRIED, I. Modelo Conceitual de Fluxo do Aquitarde Serra Geral e do Sistema Aquífero Guara- ni na Região de Ribeirão Preto (SP). 2010. 124p. Tese (Doutorado em Geologia) Instituto de GeociênciasUniversidade de São Paulo, São Paulo. 2010. 